Romantik und Religion 
Heine Studien

Herausgegeben von Joseph A. Kruse

Heinrich-Heine-Institut

der Landeshauptstadt Düsseldorf 
Christian Höpfner

\section{Romantik und Religion}

Heinrich Heines Suche nach Identität

Verlag J. B. Metzler Stuttgart - Weimar 
Die Deutsche Bibliothek - CIP-Einheitsaufnahme

Höpfner, Christian:

Romantik und Religion : Heinrich Heines Suche nach Identität / Christian Höpfner.

- Stuttgart ; Weimar : Metzler, 1997 (Heine-Studien)

ISBN 978-3-476-01581-5

ISBN 978-3-476-01581-5

ISBN 978-3-476-03727-5 (eBook)

DOI $10.1007 / 978-3-476-03727-5$

Dieses Werk einschließlich aller seiner Teile ist urheberrechtlich geschützt. Jede Verwertung außerhalb der engen Grenzen des Urheberrechtsgesetzes ist ohne Zustimmung des Verlages unzulässig und strafbar. Das gilt insbesondere für Vervielfältigungen, Übersetzungen, Mikroverfilmungen und die Einspeicherung und Verarbeitung in elektronischen Systemen.

(C) 1997 Springer-Verlag GmbH Deutschland

Ursprünglich erschienen bei J. B. Metzlersche Verlagsbuchhundlung und Carl Ernst Poeschel Verlag GmbH in Stuttgart 1997 


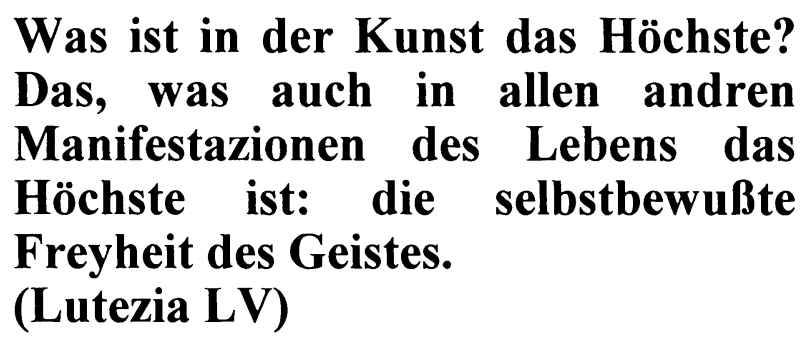




\section{Danksagung}

Die vorliegende Arbeit wurde Ende 1995 der Philologischen Fakultät der Otto-FriedrichUniversität Bamberg mit dem Titel „Romantik und Religion: Heines Identitätssuche“ als Dissertation vorgelegt.

Am Ende eines solch arbeitsintensiven Projektes gibt es viele Menschen, die mir geholfen haben und denen es nun gilt Dank zu sagen. Beginnen möchte ich mit Prof Dr. Heinz Gockel, dem Betreuer meiner Arbeit. Professor Dr. Stefan Bodo Würffel, der Zweitgutachter, half mit fachlichem Rat.

Prof. Dr. Joseph A. Kruse danke ich für die Bereitschaft, diese Arbeit in die Reihe der HeineStudien aufzunehmen. Seine Anmerkungen waren stets hilfreich und anregend.

Die Universitätsbibliothek Bamberg war mir lange Zeit Literatur- und Arbeitgeber, so daß ich mich bei den KollegInnen, vor allem bei Barbara Steinhäußer und Irmgard Sieder (Staatsbibliothek) bedanken möchte.

Arno Lembke und Dorothea Rau-Lembke sowie Maria Scharf waren und sind mir ein menschlicher Rückhalt, dessen man nicht nur bei solch einem Unternehmen bedarf.

Clemens Eichfelder und meinem langiährigen Freund Günther Zohner gebührt großer Dank für das Korrekturlesen, trotz vieler anderer Verpflichtungen im Studium bzw. Beruf.

Meiner Frau Beate danke ich für die Hilfe bei der Durchsicht und den Rückhalt, den sie mir gab und gibt.

Schließlich ist auch an die Eltern zu denken, deren Unterstützung ich mir auch während dieser Zeit gewiß sein durfte. 


\section{N H A L T S V ER Z E I C H N I S}

Einleitung.

S. 1

A. Heine und die Romantik

S. 4

I. Einleitung und Rückblick

S. 4

II. Anfänge: Begeisterung und Verfremdung

S. 5

1. Die Romantik und der Sonettenkranz

S. 5

2. Buch der Lieder

S. 17

2.1. Interpretation

S. 17

2.2. Zeitgenössische Rezeption

S. 33

III. Eigener Weg und Abrechung: Die Romantische Schule..... S. 37

1. Entstehung .................................................................. 37

2. Interpretation .......................................................... 39

3. Heine und die französische Romantik............................ S. 57

4. Zeitgenössische Rezeption .............................................. S. 59

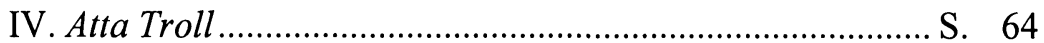

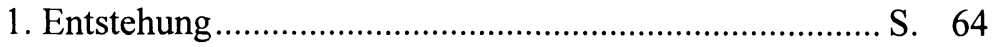

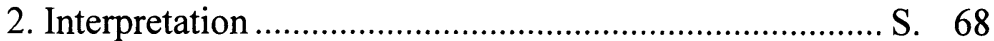

3. Zeitgenössische Rezeption ............................................ S. 84

V. Romantik in Heines später Lyrik ...................................... S. 87

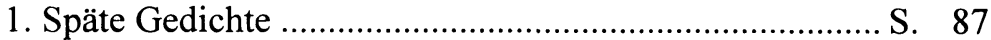

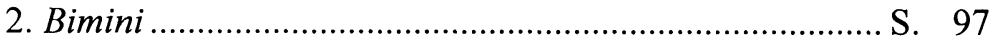

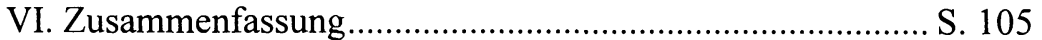

1. Die Ironie des späten Heine: romantische Ironie?........... S. 105

1.1. Die Entwicklung der Ironie im Überblick .................... S. 105

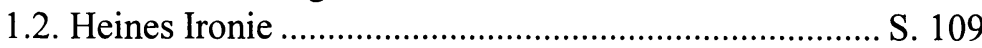

2. Heines Verhältnis zur Romantik ..................................... S. 113 
B. Der späte Heine und die Religion ……............................. S. 118

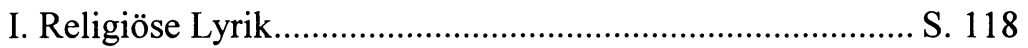

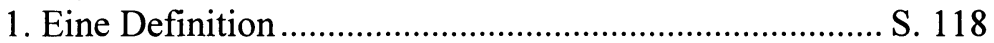

2. Religiös-geistliche Lyrik der Zeit..................................... S. 122

II. Heines religiöse Lyrik........................................................ S. 133

1. Heines religiöse Lyrik: Inhalt und Sprache .................... S. 133

1.1. Leid und Theodizee-Frage........................................... 137

1.2. Tod und mögliche Auferstehung................................... S. 157

1.3. Anrufungen Gottes und Sorge um Mathilde ................ S. 169

2. Heines Gedichte in der zeitgenössischen Rezeption....... S. 178

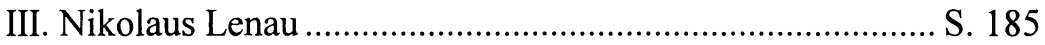

IV. Annette von Droste-Hülshoff............................................ S. 196

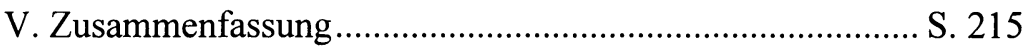

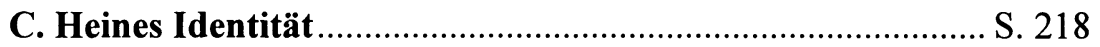

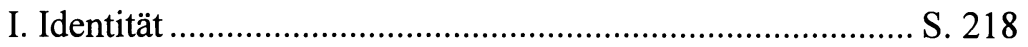

II. Heines Wege der Identität bis 1848. Ein Überblick ........... S. 222

III. Die Identitätskrise von 1848 und die neue

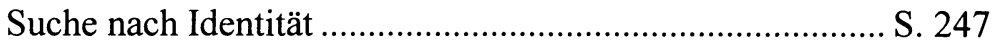

1. Die Identitätskrise ........................................................ S. 247

2. Der sterbende Heine …................................................... S. 250

2.1. Heines Religion ........................................................ S. 250

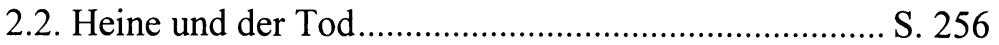

2.3. Heine und die Theodizee............................................ S. 264

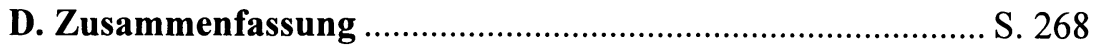

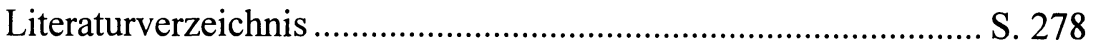

Abkürzungen und Zitierweise..................................................... S. 315

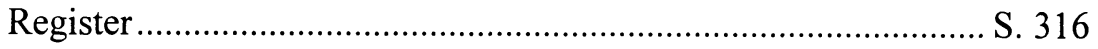

